Available online at https://jurnal.stmikroyal.ac.id/index.php/jurdimas

\title{
PEMANTAPAN KARANG TARUNA DAN PEKAN AMBYAR DESA MORANG KEC. KARE KAB. MADIUN
}

\author{
Robby Sandhi Dessyarti ${ }^{1 *}$, Dian Citaningtyas Ari Kadi ${ }^{1}$, Apriyanti ${ }^{1}$ \\ ${ }^{1}$ Program Studi Manajemen, Universitas PGRI Madiun \\ email: *robbeyvan@gmail.com
}

\begin{abstract}
The organization is a social entity that consciously coordinates and has boundaries and has an ongoing identity to achieve organizational goals. One of them is Karang Taruna Village Morang which is a forum that has a function as guidance and development of the village's economic potential. The youth organization in Village Morang has a superior program in the form of pekan ambyar. However, the lack of understanding and knowledge in terms of organization, administration, and finance meant that this program was limited to planning. This makes the reason for the need to strengthen youth organizations. The method used in community service programs is in the form of community education training in the form of an understanding of organization, administration, and finance. The results achieved in this activity were that youth organizations could understand in terms of organization, administration, and financial aspects. The implementation of the flagship program pekan ambyar is one of the iconic activities that are competitive and makes the Village Morang Maju.
\end{abstract}

Keywords: administration; financial; karang taruna; organization

\begin{abstract}
Abstrak: Organisasi merupakan sebuah entitas sosial yang secara sadar melakukan koordinasi dan memiliki batasan serta memiliki identitas yang berkelanjutan untuk mencapai tujuan organisasi. Salah satunya adalah karang taruna desa Morang dimana merupakan sebuah wadah yang memiki fungsi sebagai pembinaan dan pengembangan potensi perekonomian desa. Karang taruna yang berada di desa Morang memiliki sebuah program unggulan berupa pekan ambyar. Namun kurangnya pemahaman dan pengetahuan dalam segi organisasi, administrasi dan keuangan menjadikan program ini sebatas perencanaan. Hal ini menjadikan alasan perlunya dilakukan pemantapan karang taruna. Metode yang digunakan dalam program pengabdian kepada masyarakat berupa pelatihan pendidikan masyarakat berupa pemahaman akan organisasi, administrasi, dan keuangan. Hasil yang dicapai dalam kegiatan ini adalah karang taruna dapat memahami dalam segi organisasi, segi administrasi, dan segi keuangan. Terlaksananya program unggulan pekan ambyar sebagai salah satu kegiatan yang iconic berdaya saing serta menjadikan desa Morang Maju.
\end{abstract}

Kata kunci: administrasi; keuangan; karang taruna; organisasi 
Jurdimas (Jurnal Pengabdian Kepada Masyarakat) Royal

Vol. 4 No. 3, September 2021, hlm. 313 - 318

ISSN 2614-7912 (Print)

DOI: https://doi.org/10.33330/jurdimas.v4i3.990

ISSN 2622-3813 (Online)

Available online at https://jurnal.stmikroyal.ac.id/index.php/jurdimas

\section{PENDAHULUAN}

Organisasi merupakan suatu entitas sosial yang secara sadar terkoordinasi dan memiliki batas yang dapat diidentifikasi keberadaannya, serta memiliki identitas yang berfungsi secara relative berkelanjutan untuk mencapai tujuan oganisasi (Kusdi, 2009). Bentuk organisasi dapat dilihat melalui disiplin ilmu diantaranya melibatkan ilmu ekonomi, manajemen dan teknik. Kaitannya dalam hal ini organisasi membutuhkan sebagai mana cara pengadministrasian dan teknik manajemen. Administrasi adalah sarana untuk mengerakkan orgnisasi dengan tugas agar dapat mengarah ke tujuan organisasi sendiri. Sedangkan manajemen adalah sarana bagi organisasi untuk dapat secara efektif dan efesien bekerja untuk mencapai tujuan organisasi.

Pada umumnya organisasi akan memanfaatkan berbagai sumber daya tertentu dalam rangka mewujudkan tujuan yang telah ditetapkan bersama. Sejalan dengan pendapat (Dessyarti, 2018) pada penelitiannya menyatakan bahwa asset penting dalam pengembangan organisasi adalah sumber daya manusianya itu sendiri. Sehingga organisasi tidak terlepas dari peran anggota ataupun individu yang bersama-sama membentuk suatu kelompok yang memiliki identitas.

Karang taruna merupakan salah satu organisasi yang telah dikenal bagi masyarakat khususnya perkotaan maupun perdesaan. Sejalan dengan penelitian (Arifianto, 2017) menyatakan karang taruna merupakan suatu organisasi yang bergerak ditingkat desa maupun kelurahan yang menjadi wadah atau tempat bagi generasi muda untuk lebih mengembangkan dirinya sendirinya. Wadah pembinaan dan pengembangan yang dimaksudkan adalah sejauh mana upaya dalam mengembangkan perekonomian dengan pendayagunaan sumber daya manusia maupun sumber daya alam. Sebagai salah satu organisasi kepemudaan karang taruna memiliki pedoman dasar dan rumah tangga tentang struktur pengurus dan masa jabatan masing-masing wilayah. Mulai dari desa atau kelurahan sampai pada tingkat nasional.

Menurut (Arif \& Adi, 2014) pada penelitiannya menyatakan bahwa peranan karang taruna yaitu menghimpun, menggerakkan, dan menyalurkan peran sebagai generasi dalam membangun kesejahteraan sosial. Karang taruna sendiri merupakan salah satu mediator dan motivator dalam pembangunan perekonomian desa/kelurahan yang tidak bisa dipisahkan. Sehingga karang taruna harus mempunyai kontribusi dalam pemberdayaan dan pembangunan bangsa. Mengenal desa Morang merupakan desa yang termasuk agragis dimana beralokasi di wilayah kecamatan Kare, kabupaten Madiun, Jawa Timur dengan jumlah penduduk sebanyak \pm 5.536 Jiwa.

Dimana desa Morang terbagi menjadi 3 (tiga) dusun diantaranya: Morang, Kepak, dan Janget. (Sumber: id.wikipedia.id) Yang masing-masing memiliki organisasi kepemudaan yaitu karang taruna. Karang taruna yang dimiliki oleh desa Morang bertujuan untuk memberikan pembinaan dan pemberdayaan kepada para remaja atau warga sekitar misalnya dalam bidang keorganisasian, ekonomi, olahraga, keterampilan, keagamaan, dan kesenian. Salah satunya program kerja unggulan karang taruna ialah "Pekan Ambyar". Adapun sasaran dalam kegiatan ini yaitu UMKM desa Morang, Petani, Peternak, Wirausahaan, Pedagang, dan masyarakat sekitar.

Kegiatan pekan ambyar seharusnya diharapkan dapat meningkatkan perenokonomian serta menunjukkan 
Available online at https://jurnal.stmikroyal.ac.id/index.php/jurdimas

potensi hasil desa dan menjadi salah satu icon keunggulan wisata. Namun pada kenyataan kegiatan ini tidak pernah terwujud maupun sebatas perencanaan dan hanya sebatas wacana. Adapun kekurangan pada keorganisasian karang taruna tersebut, diantaranya segi administrasi: mencakup surat pernyuratan, pengarsipan, dan proposal kegiatan, segi organisasi meliputi struktur organisasi yang tidak jelas, rantai komunikasi yang tidak berjalan lancar, masih terlihatnya tupang tindih antara tugas dan tanggung jawab antara satu dengan yang lainnya, dan segi keuangan diantaranya laporan pertanggung jawaban program kerja yang belum akuntabel, kurangnya pengetahuan tentang pengantar akuntansi dan pembuatan proposal kegiatan.

Berdasarkan penjelasan yang telah dikemukakan sebelumnya maka melalui program pengabdian kepada masyarakat bersama mahasiswa $\mathrm{KKN}-\mathrm{T}$ Bina desa berinisiatif memberikan pemantapan dan pelatihan karang taruna yang melibatkan pemateri yang berkompeten. Guna meningkatkan pemahaman dan pengetahuan dibidang administrasi, organisasi, dan keuangan (Hutahaean, Azhar \& Mulyani, 2020).

Kegiatan pemantapan karang taruna pada desa Morang diharapkan dapat meningkatkan serta mengembangkan potensi yang dimiliki oleh pemuda/remaja ataupun warga sekitar guna memperkuat kemampuan daya yang dimiliki agar nantinya dapat mencapai kemandirian.

\section{METODE}

Lokasi kegiatan pengabdian masyarakat pada organisasi kepemudaan bertempat di Balai desa Morang dengan jumlah peserta 50 peserta dari keorga- nisasian yang berada di desa. Metode yang digunakan adalah metode berupa pendidikan masyarakat dengan menerapkan kegiatan pelatihan yang dibantu oleh mahasiswa KKN T- Bina desa Tahun. 2020 (Morelli, 2015).

\section{Pelaksanaan Kegiatan}

Kegiatan pengabdian masyarakat dilaksanakan dengan memberikan materi yang melibatkan pemateri yang ahli dibidangnya agar dapat meningkatkan pemahaman akan pengadminitrasian, keorganisasian dan penyusunan proposal atau pelaporan keuangan kegiatan (Hutahaean, Azhar \& Mulyani, 2020). Hasil penilaian kemampuan bagi peserta yang mengikuti kegiatan pemantapan karang taruna yaitu karang taruna dapat memahami proses administrasi maupun proposal kegiatan, laporan pertanggungjawaban dan dapat terealisasinya kegiatan "Pekan Ambyar" desa Morang sebagai salah satu event yang iconic berdaya saing serta menjadikan desa Morang Maju.

\section{PEMBAHASAN}

Dalam pembahasan pelaksanaan kegiatan pemantapan karang taruna sebelumnya dilakukan identifikasi masalah, sosialisasi, pelatihan serta penentuan dan pelaksanaan kegiatan pekan ambyar selama kurang lebih 5 minggu, Sedangkan untuk waktu/lama kegiatan pengabdian dilaksanakan selama 2 hari pada minggu ketiga untuk pelatihan dan agenda "Pekan Ambyar" selama 1 hari pameran pada minggu kelima.

Adapun rincian jadwal pada minggu pertama dilakukan identifikasi masalah sebagai langkah awal menentukan permasalahan terkait administrasi, organisasi dan keuangan yang terjadi di 
Available online at https://jurnal.stmikroyal.ac.id/index.php/jurdimas

karang taruna pada program kerja unggulan. Selanjutnya minggu kedua melaksanakan tahapan sosialisasi untuk menentukan kegiatan pemantapan karang taruna.

Agenda pada minggu ketiga yaitu melaksanakan kegiatan pemantapan karang taruna dengan memberikan pemahaman materi pertama tentang bagaimana struktur organisasi, kepemimpinanan, dan efektifitas organisasi dalam birokrasi khususnya karang taruna. Menurut (Robbins, 2017) menyatakan bahwa struktur organisasi merupakan suatu cara yang mana tugas pekerjaan secara formal dibagikan, dikelompokkan, dan dikoordinasikan dalam sebuah organisasi agar mencapai tujuan bersama.

Pada sesi selanjutnya materi kedua yaitu tentang administrasi dimana membahas seputar bagaimana administrasi manajemen yang baik meliputi pembuatan proposal kegiatan, suratmenyurat, serta tahapan pengajuan proposal. Menurut (Nunung, 2020) pada penelitiannya administrasi merupakan bentuk aktivitas yang meliputi catatmancatat, surat-menyurat, pembukuan sederhana, ketik-mengetik dan kegiatan lain yang sifatnya ketatausahaan.

Kemudian materi ketiga yang terakhir terkait dengan keuangan yang membahas seputar strategi penyusunan anggaran, penyusunan laporan keuangan dilanjutkan laporan pertanggungjawaban keuangan. Dimana akuntansi merupakan prosedur untuk mengakui pencatatan dan kosrespodensi bursa keuangan dari suatu organisasi. Sedangkan tujuan dari pelaporan keuangan untuk menyediakan informasi yang menyangkut posisi keuangan, kinerja bahkan perubahan yang ada dalam anggaran sebagai pengambilan keputusan (Arif, Abubakar, \& Wibowo, 2008).

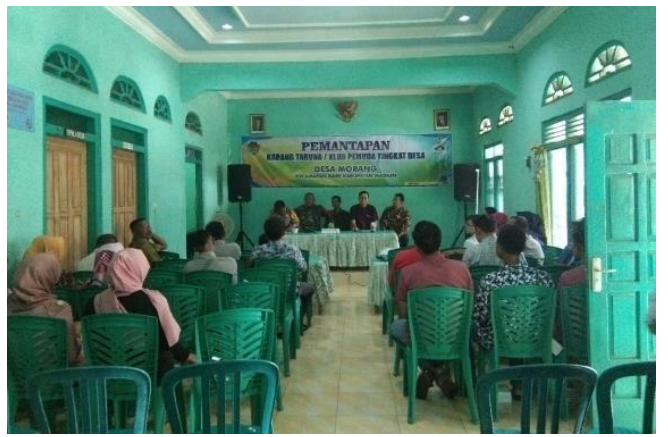

Gambar 1. Penyampaian materi pertama terkait Keorganisasian

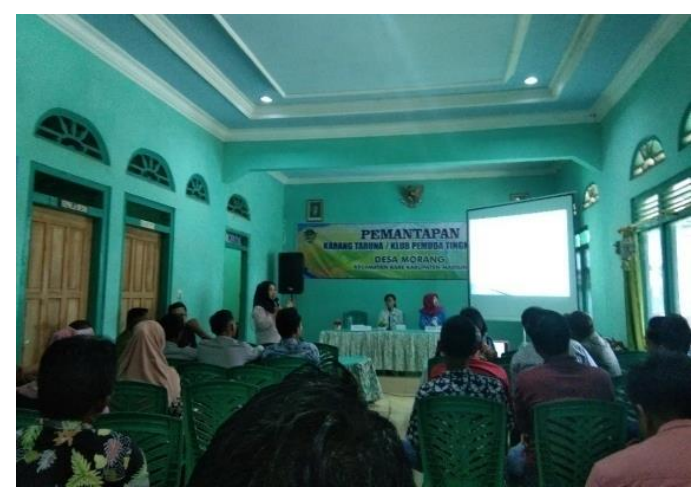

Gambar 2. Penyampaian materi kedua terkait Administrasi

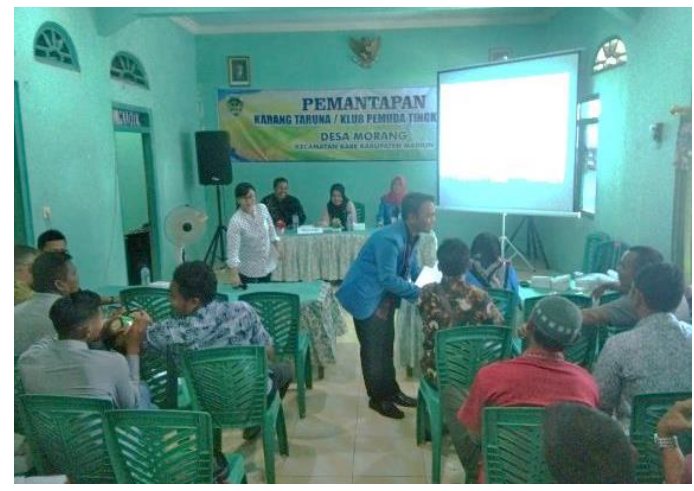

Gambar 3. Penyampaian materi ketiga terkait Keuangan

Hasil yang didapat dari kegiatan pemantapan karang taruna meliputi karang taruna dapat memahami tentang keorganisasian, administrasi, dan keuangan ditunjukkan dengan sangat antusias dan termotivasi membuat program kerja unggulan "Pekan Ambyar". Kemudian 
setelah pelaksanaan pemantapan karang taruna agenda minggu keempat disepakatinya kegiatan program kerja unggulan dimana mahaisswa KKN-T Bina desa berkolaborasi dengan BUMDES, Perangkat desa, UMKM, Warga sekitar dan pihak sponsor.

Pada agenda minggu kelima terselenggaranya program kerja unggulan "Pekan Ambyar" yang dibuka langsung oleh Camat Kare. Adapun luaran kegiatan ini diharapkan dapat mengenalkan hasil UMKM desa Morang, dapat meningkatkan kesejahteraan masyarakat, dan menjadikan kegiatan ikonik agenda bulanan yang terpublikasi melalui media massa.

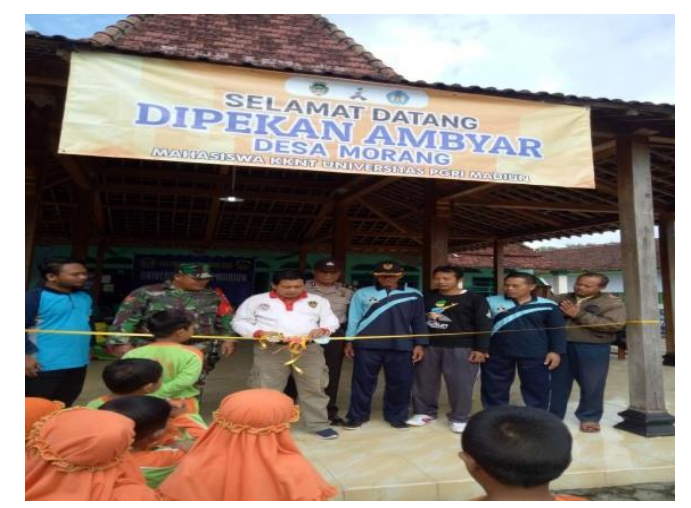

\section{Gambar 4. Terlaksananya program kerja unggulan "Pekan Ambyar" di desa Morang.}

\section{SIMPULAN}

Program pengabdian kepada masyarakat dengan agenda kegiatan pemantapan karang taruna dapat disimpulkan bahwa hasil penilaian kemampuan rata-rata kemampuan peserta sekitar 90\% memahami materi yang telah disampaikan pada saat pemantapan karang taruna. Meliputi karang taruna dapat menjalankan organisasi sesuai tugas dan strukturnya, memahami pentingnya administrasi dalam sebuah organisasi, me- mahami strategi pembuatan proposal dan pelaporan keuangan dan terlaksananya program kerja unggulan yang terpublikasi di media massa sebagai salah satu agenda wisata desa Morang Maju.

\section{UCAPAN TERIMAKASIH}

Ucapan terimakasih diberikan kepada Bapak Tarnu selaku Camat Kare, PLT desa Morang Bapak Tarmidi beserta jajaran perangkat desa Morang, dan pihak-pihak yang terkait dalam program pengabdian kepada masyarakat mulai dari awal hingga akhir kegiatan pelaksanaan.

\section{DAFTAR PUSTAKA}

Arif, Abubakar, \& Wibowo. (2008). Akuntansi Keuangan Dasar 2. Jakarta: PT. Grasindo.

Arif, M. R., \& Adi, A. S. (2014). Peran Karang Taruna dalam Pembinaan Remaja di Dusun Candi Desa Candinegoro Kecamatan Wonoayu Kabupaten Sidoarjo. Kajian Moral dan Kewarganegaraan, Volume 1 (Nomor 2), 190-205.

Arifianto, R. (2017). Peran Karang Taruna dalam Pemberdayaan Pemuda melalui Pelatihan Karawitan Gamelan Jawa Dusun Plumbon Kelurahan Ngadirejo Kecamatan Eromoko Wonogiri. Jurnal Pendidikan Luar Sekolah, Edisi Vol VI Nomor 02, 134-146.

Dessyarti, R. S. (2018). Pengaruh Gaya Kepemimpinan, Komitmen Organisasi, Budaya Organisasi terhadap Kepuasan Kerja dan Kinerja Karyawan Pemasaran (pada Dealer Motor PT Suzuki 
Jurdimas (Jurnal Pengabdian Kepada Masyarakat) Royal

Vol. 4 No. 3, September 2021, hlm. 313 - 318

Available online at https://jurnal.stmikroyal.ac.id/index.php/jurdimas

Cabang Madiun dan Ngawi). EKOMAKS : Jurnal Ilmu Ekonomi, Manajemen, dan Akuntansi, Volume 7 September (Nomor 2), 112-124. doi: https://doi.org/10.33319/jeko.v7i2

Hutahaean, J., Azhar, Z., \& Mulyani, N. (2020). Pelatihan Aplikasi Powerpoint Bagi Guru Dan Staf SD Negeri 010240 Pematang Cengkring. Jurdimas (Jurnal Pengabdian Kepada Masyarakat) Royal, Vol. 3 (No. 2), hlm 147 154. doi: https://doi.org/10.33330/jurdimas. v3i2.516
Kusdi. (2009). Teori Organisasi dan Administrasi. Jakarta: Penerbit Salemba Humanika.

Morelli, N. (2015). Challenges In Designing and Scaling Up Community Services. The Design Journal, 18(2), 269-290. doi: https://doi.org/doi.org/10.2752/17 5630615X14212498964394

Nunung, A. (2020). Administrasi, Organisasi dan Manajemen. Syntax Computama: Cirebon.

Robbins, S. P., \& Judge, T. A. (2017). Perilaku Organisasi. Jakarta: Penerbit Salemba Empat. 